Acta Hispanica (2018) 23: 243-259

\title{
COMPONENTES LINGÜÍSTICOS DE LA CHILENIDAD: LEXICOLOGÍA
}

\author{
MIRCEA-DorU BRANZA
}

Universidad de Bucarest

\begin{abstract}
Resumen: Las diferentes variedades diatópicas del español se caracterizan no sólo por diferentes fenómenos de variación fonética y morfo-sintáctica, sino, sobre todo, por una rica variación léxica. En el caso de la variedad chilena, sus rasgos característicos son, por lo general, de índole léxica y se deben a contactos lingüísticos específicos de dicha área geográfica, ausentes o menos frecuentes en otras áreas: el contacto con el quechua, aimara, mapuche (o mapudungún), alemán, gitano o con la variedad argentina del español. La existencia de tales préstamos en la variedad chilena del español se explica por la evolución histórico-cultural de la República de Chile.
\end{abstract}

Palabras clave: préstamos léxicos, interferencias léxicas, alemanismos, gitanismos, quechuismos, mapuchismos, argentinismos

\begin{abstract}
The different diatopic varieties of Spanish are characterized by different phenomena of phonetic and morpho-syntactic variation, and, more importantly, by a rich lexical variation. In the case of the Chilean variety, its characteristic features are, in general, of a lexical nature and are due to specific linguistic contacts within Chile's geographical area, which are absent or less frequent in other areas: contacts with Quechua, Aymara, Mapuche (or mapudungun), German, gypsy, or with the Argentine variety of Spanish. The existence of such lexical loans in the Chilean variety of Spanish can be explained by the Republic of Chile's historical and cultural evolution.
\end{abstract}

Keywords: lexical loans, lexical interferences, Germanisms, gypsies, quechuisms, mapuchisms, argentinisms

Quienes conocen mi actividad científica se habrán dado cuenta de que en los últimos años mis publicaciones han versado sobre temas de lingüística relacionados con los fenómenos de variación lingüística propios de la morfosintaxis del español hablado en España e Hispanoamérica, así que van a estar sorprendidos de que ahora voy a abordar el léxico de la variedad chilena del español. Esto tiene que ver, por una parte, con un motivo sentimental, el inmenso afecto que siento por este país que, a lo largo de los años, he podido conocer bastante bien, y otro científico, a saber la relación muy estrecha entre la historia de una comunidad étnica y su idioma, especialmente el léxico de dicho idioma. 
El léxico del español, como el de cualquier otro idioma es el resultado de la historia de las influencias de otras lenguas, sea debido a contactos directos, sea especialmente en las últimas décadas- indirectos. Como toda Hispanoamérica, Chile -tal como lo conocemos hoy en día- es el resultado de un largo proceso de mestizaje entre la población indígena -mapuche, quechua o aimara-, para recordar sólo los grupos étnicos más numerosos e importantes, y los europeos que durante casi cinco siglos han emigrado a este país. Después de las incursiones de Diego de Almagro (1535) y Pedro de Valdivia (1540) empieza la conquista de Chile y una tímida colonización, debido sobre todo a la resistencia de los indígenas.

Durante los siglos XVI-XVIII emigraron a Chile especialmente andaluces, extremeños y castellanos, a diferencia de los dos siguientes siglos cuando emigraron a Chile tanto vascos, como asturianos, mallorquines, asturianos, además de castellanos y andaluces. En los siglos XIX y XX todos los países hispanoamericano, Chile incluido, recibieron muchísimos inmigrantes oriundos de España, Italia, Gran Bretaña, pero también del Imperio Otomano. Esto significa, por una parte, que el léxico de la variedad chilena del español cuenta con una amplia herencia del léxico español peninsular, o sea términos compartidos en España y Chile y, por otra parte términos propios de Chile.

En el presente estudio me propongo analizar la influencia de algunos grupos étnicos en el léxico del español en general y del español que se usa en Chile en especial, a saber términos de origen indígena, germánico, neerlandés, argentino y gitano.

Los indigenismos forman también parte de los rasgos característicos del léxico usado en Chile. En el actual territorio de Chile se hablaron sobre todo tres idiomas indígenas: el quechua y el aimara en el Norte y el mapuche en el Sur.

Debido a la influencia que ejerció el Imperio Incaico en el Norte de Chile, además de la toponimia de esta área, en otros campos léxicos, se encuentran más de doscientos quechuismos cuyo uso es todavía actual, sobre todo en la región de Tarapacá. Se trata, generalmente, de chilenismos que tienen otro correspondiente en el español peninsular (Branza, 2017), entre los cuales figuran cancha < kancha: 'terreno, espacio, lugar destinado al juego de pelota o a peleas de gallos'; cototo < k'oto: 'chichón, bulto en la cabeza', de donde ser cototo = ser inteligente / estudioso; huaso / guaso < quechua / mapuche buasu 'anca (de caballo), campesino de Chile'; 
guagua < wáwa 'niño de pecho'; puna < 'mareo por alturas', anticucho < anti 'Andes' + (c)ucho 'corte de carne o ají' = 'trozos de corazón de vaca que se comen asados a la parrilla'; charqui < cha'rki 'tasajo' (pedazo de carne seca y salada o acecinada para que se conserve)'; chacra < chacra 'granja'; guano < buanu 'materia excrementicia de aves utilizada como abono en la agricultura'; pampa $<$ pampa 'cualquiera llanura que no tiene vegetación arbórea'; cochaynyo < kochu laguna yuyu hortaliza 'alga marina'; choclo < choccllo ('maíz') 'mazorca'; papa < papa 'patata'; palta < pallta 'aguacate'; poroto < purutu 'frijol'; zapallo < sapallu 'calabaza, calabacín', etc.

Entre los mapuchismos, algunos son regionalismos, propios del Sur de Chile, pero también se encuentran voces de origen mapuche usadas en todo el territorio de Chile en la variante estándar: chauchas (en Chile, 'papa temprana' en mapudungun) 'moneda sin valor'. No tengo ni una chaucha; cabuin $<$ cahuin 'reunión de los caciques', que en la variedad chilena actual tiene el significado de 'reunión de gente para beber y embriagarse; comentario disparatado'; guata < buata 'panza, barriga'; machi < machi 'curandera o curandero de oficio'; malón < maleu, malecau 'hacer hostilidad al enemigo'; era el asalto sorpresivo de los indios entre tribus enemigas. El término designa en la actualidad el asalto pacífico de una casa, de un amigo, por ejemplo, para organizar una fiesta. un pichintún < pichi 'un poco, una pequeña porción' ("No lave un pichintún, lave más ropa»); pololo < piulliu 'mosca alrededor de la fruta, novio'; gaucho < cauchu 'amigo, argentino'; poncho < pontro 'tela de lana prenda de abrigo cuadrada, con una abertura en el centro para pasar la cabeza', prenda muy importante en Chile; esta voz se encuentra en muchos refranes o giros: A mi nadie me pisa el poncho (No me dejo intimidar.), Donde el diablo perdió el poncho (Donde Cristo dio las tres voces; en un lugar muy remoto.), Somos todos honrados, pero el poncho no aparece (expresión que se usa en los casos en que, dentro de un grupo se ha cometido algo ilícito y todos claman por su inocencia, como si nadie fuera responsable del delito cometido); charquicán < quechua charqui 'carne secada', mapundungun cancan 'asado' = 'guiso con charqui, maíz, patatas'; pino < pinu el relleno de carne picada, cebolla, huevo duro, aceitunas y pasas de las empanadas', etc.

Muchas de estas voces han sustituido en su uso al equivalente del español europeo de modo que su utilización es casi exclusiva, lo cual puede causar malentendidos muchas veces en la persona que no las conoce. 
Debido a su escasa población, el joven estado chileno promulgó en 1845 La ley de la inmigración selectiva, que, de hecho, era la ley de la colonización, y que estipulaba varias ventajas económico-financieras (gastos de viaje a cargo del gobierno de Chile, distribución de tierras, medios de financiación, exención de pagar contribuciones, catastro e impuestos durante un período de 20 años): gracias a dicha ley, empieza la inmigración alemana a Chile que a lo largo del siglo XIX hizo posible que entre 30000 y 40000 colonos -entre alemanes, austríacos y suizos- se establecieran en el sur de Chile: los alemanes y los suizos, por lo general, en las provincias de Valdivia (la XIV ${ }^{a}$ región Los Ríos) y Osorno (la $\mathrm{X}^{a}$ región Los Lagos) , y los austríacos aún más al sur, más exactamente, en la provincia de Llanquihue (la misma $\mathrm{X}^{\mathrm{a}}$ región).

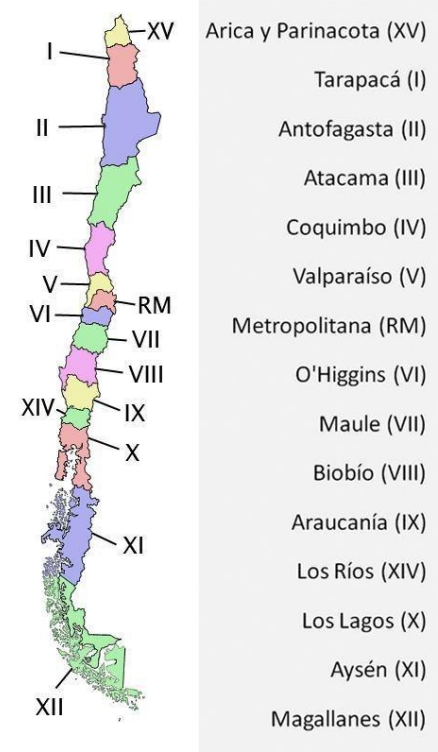

Por la distancia entre estas provincias, si no desiertas, escasamente pobladas del centro (más desarrollado desde el punto de vista económico) y sur del país, la comunicación con la capital fue muy escasa al principio, lo cual explica el relativo aislamiento de los colonos germanos y el poco contacto con los hispanohablantes y los aborígenes. Su espíritu organizativo y de disciplina hizo posible la fundación de varios colegios y asociaciones alemanes que funcionan hasta hoy en día. La influencia alemana en Chile es muy importante, desde la arquitectura hasta la cultura. 
Aunque los inmigrantes alemanes tenían contactos muy estrechos con sus vecinos chilenos, se mezclaron muy poco con éstos por motivos especialmente religiosos (la mayoría de los colonos eran protestantes, porque los obispos católicos no estuvieron de acuerdo con la emigración a Chile de sus hijos espirituales). Mientras que los colonos católicos se integraron rápidamente, de modo que hacia finales del siglo XIX estaban ya asimilados, los protestantes, se aislaron y vivieron durante casi todo este período en un estado de endogamia, lo cual les permitió conservar también la lengua de sus tatarabuelos.

Especialmente en el área de Llanquihue, hay todavía descendientes de colonos que siguen hablando el alemán traído a Chile por sus antepasados, influido, naturalmente, por la lengua mayoritaria. Dicha variedad de alemán, conocida como Lagunen (Laguner o Launa)-Deutsch, ha sufrido la influencia de la lengua mayoritaria y, por lo tanto, son bastante frecuentes las interferencias léxicas con el español. Se trata, por lo tanto, de una variedad de alemañol, pero no de Alemania, sino de Chile. A continuación unas cuantas muestras de interferencias léxicas:

(1) L-D Dieses international operierende Unternehmen macht uns starke Kompetenz. Al. Dieses international operierende Unternehmen macht uns starke Konkurren: Esp. Esta empresa que opera internacionalmente nos hace una fuerte competencia.

En el ejemplo (1) se observa que en la oración producida en la variedad alemana de Chile (L-D) aparece el término *Kompetenz que no existe en alemán. Bajo la presión del término español competencia, el término alemán correcto Konkurrenz ${ }^{1}$ (sinónimo de Wettbewerb o Rivalität (préstamo del francés rivalite), que es el sustantivo derivado del verbo konkurrieren $<$ Lat. CONCURRERE, fue sustituido por un préstamo del castellano.

(2) L-D Kannst du bitte ein paar Papen schälen?

Al. Kanst du bitte ein para Kartoffeln schälen?

Esp. ¿Puedes pelar, por favor, un par de patatas?

En (2) bajo la influencia del término papa que se usa en toda Hispanoamérica para denominar la patata (Esp. europeo, cruce de papa-voz de origen quechua- y del vocablo taíno batata) desapareció el correspondiente alemán Kartoffeln para hacer lugar a *Papen.

${ }^{1}$ Véase para los términos alemanes Etymologisches Wörterbuch des Deutsches. 
(3) L-D Die Vacken müssen jeden Tag geletschert werden.

Al. Die Kühe müssen jeden Tag gemolken werden.

Esp. Las vacas hay que ordeñarlas cada día.

En (3) aparecen dos ejemplos de interferencia: *Vacken (< Esp. vaca por el Al. Kuh, plural Kühe) y $*$ geletschert, participio del verbo $*$ letschern formado a partir del sustantivo español leche. En el español ecuatoriano y en el mexicano existe un verbo lechar (derivado del sustantivo leche) que significa dar leche / mamar o blanquear las paredes con agua de cal.

(4) L-A Wir müssen nicht zur pastelería gehen, es ist zu teuer, wir machen unser Brot und allerlei Gebäck selbst.

Al. Wir müssen nicht in die Bäckerei gehen, es ist zu teuer, wir machen unser Brot und allerlei Gebäck selbst.

Esp. No tenemos que ir a la panadería, es demasiado caro, hacemos nuestro pan y todo tipo de galletas nosotros mismos.

En (4) aparece el término * pastelería en lugar de Bäckerei, préstamo no adaptado del castellano.

Otros ejemplos de interferencia lingüística son *examen (< Esp. examen médico) por 'ärztliche Untersuchung' (investigación médica) $\mathrm{u} *$ ordinär $(<$ Esp. ordinario) por 'gewöbnlich, herkömmlich, normal va'.

Como es de esperar, los jóvenes chilenos de ascendencia alemana destacan por un fenómeno de fuerte migración (por razones de educación o de trabajo), lo cual favoreció un gran número de matrimonios mixtos en los cuales, en la gran mayoría de los casos la lengua de contacto es el castellano. Por consiguiente, un cambio de idioma del alemán al español, entre los descendientes de alemanes, es un fenómeno no solo probable sino también real, ya que se encuentran en una fase de pérdida progresiva de la lengua de sus antepasados y, como en el caso de otras comunidades lingǘsticas poco numerosas rodeadas por hablantes de la lengua dominante, es muy probable que las condiciones de cambio lingüístico a las que referimos aumenten en el futuro. 
Pese a la pérdida progresiva de la lengua, la influencia alemana, sobre todo en el sur de Chile es todavía grande, en la arquitectura y gastronomía que dejan ver una fuerte tradición alemana; así se explica la presencia de unos términos propios de la gastronomía alemana en el español de Chile; Kuhen, Strudel así como Bretzel, forman ya parte de la tradición pastelera de Chile.

El español, como, por lo general, los idiomas románicos occidentales, cuenta con muchos préstamos de origen germánico, que tienen una larga historia que empieza con el contacto lingüístico entre los godos y la población hispanorromana, galorromana o italorromana. En el uso actual del español (de Chile también) están presentes numerosos términos de origen alemán ${ }^{2}$, con una frecuencia de uso variable, que cubren prácticamente todos los campos de la actividad humana. $\mathrm{He}$ aquí unos cuantos ejemplos:

Entre estos términos se encuentran, entre otros:

albergue s. XIII, < bajo latín HERIBERGIUM < gót. *HARIBAIRGO 'campamento, alojamiento' cuenta con cognados en fr. med. herberg, herberge > fr. mod. auberge, pt. albergue, it. albergo (v. al. Herberge, nl. herberg). arpa (instrumento músico) $\pm 1250<$ bajo latín HARPA < gót. HARPA instrumento que usaban los godos', con los equivalentes fr. harpe, it. arpa, pt. harpa (v. al. Harfe, nl. harp, ingl.harp).

guerra 1037 < germ. WERRA 'discordia' > pt. guerra, fr. guerre, it. guerra (v. nl. war 'desorden, confusión', ingl war 'guerra', al. Wirre 'confusión').

orgullo $\pm 1270<$ germ. *URGOLI (a través del cat. orgull) it. orgoglio, pt. orgulho, fr.orgueil que no tiene cognados en las lenguas germánicas, que usan otros lexemas al. Stolz, nl. trots, ingl. pride.

robar \pm 1140 < bajo latín RAUBARE (s. VIII) < germ. RAUBON 'saquear' con los cognados fr. rober, it. rubare, pt. roubar (v. al. rauben, raufen, ingl. to reave, nl. (be)roven).

La Edad Media no fue el único período en el cual los germanismos encontraron su lugar en el español. Con la evolución de las ciencias, otros germanismos se adaptaron a la fonología y morfología del español y entraron recientemente:

agasajar, por ejemplo, atestiguado en el s. XVI < gasajo (1330) 'placer en compañía' < gót. *GASALI ' compañía' v. al. Geselle 'compañero', nl. gezel 'compañero'.

2 Más exactamente 346 de términos véase Prieto, 2002:141-237. 
Probablemente relacionado con la llegada de Carlos I de Habsburgo a España, empiezan a usarse otros préstamos del alemán:

brindar s. XVI < esp. brindis < al. ich bring dir's 'te ofrezco (algo)'. burgomaestre $1548<$ al. Bürgermeister 'alcalde'.

A partir del siglo XVIII en Europa se observa un desarrollo extraordinario de la ciencia y técnica. De ahí también un gran número de préstamos del alemán, especialmente en estos campos de actividad:

Técnica y ciencia:

bencina < al. Benzin 'gasolina'. "En tanto, en nuestro país los automovilistas están sacando barata las reiteradas alzas que muestra el petróleo en el mercado internacional. Mientras que la bencina de 93 octanos no variará, la de 95 bajará en $\$ 4$ y la de 97 octanos en $\$ 5$ por litro”. (El Mercurio, 9-X-2004, B1, c.2).

diésel < al. Diesel del n. p Rudolf Christian Karl Diesel (1858-1913), ingeniero alemán, inventor del carburante diésel y del motor de combustión de alto rendimiento que lleva su nombre, el motor diésel.

bismuto $1756<$ al. Bismut o Wismuth.

cobalto $1832<$ al. Kobalt por conducto del fr. cobalt.

níquel 1884 < al. Nickel y este del isl. hnikkil 'uno de los duendes de las minas'. Los mineros suecos que lo descubrieron desilusionados de su mala calidad lo nombraron hnikkil. it. nichel, nl. nikkel, it. nichel, fr. nickel.

niobio $1900<$ al. Niobium y este del lat. NIŎBE, hija de Tántalo (por hallarse este metal siempre junto al tantalio).

zinc finales del s. XVIII < al. Zink por conducto del fr. zinc, it. zinco, pt. zinco. enzima s. XX < al. Ensym, fr. ensyme.

barbitúrico s. XX < al. Barbitursäure por conducto del fr. barbiturique.

En la gastronomía, artes y política también hay préstamos del alemán:

vals $1843<$ al. Walzer (derivado de walzen 'dar vueltas' por conducto del fr. vals. vampiro $1843<$ fr. vampire < al. Vampir o Vampyr < húng. vámpir.

chucrut $\mathrm{s}$. XX $<$ al. Sauerkraut por conducto del fr. choucrout.

bandoneón $\pm 1930<$ al. Bandoneon, acrónimo de Heinrich Band 1821-1860 quien lo inventó, Harmonika y Akkordeon.

Yiddish $<$ al. Yddisch por conducto del ingl. Yiddish.

hámster $<$ al. Hamster.

lied $<$ al. Lied 'canción lírica breve cuya letra es un poema al que se le ha puesto música, escrita para voz solista y acompañamiento, generalmente, de piano. 
nazi < al. Nazị, abreviación de Nationalsorialist, que significa miembro o simpatizante del Partido Nacional Socialista Obrero Alemán. "El Canciller Helmut Kohl [...] invitó al Presidente Reagan a conmemorar no sólo a las víctimas de los nazis, [...]." (El Mercurio 29-VIII-98, Reportajes del Sábado, p. D8, cc. 1 y 2).

nazismo < (al. Nazismus, abreviación de Nationalsozialismus. La doctrina política y nombre del movimiento promovido por el Partido Nacional Socialista Obrero Alemán. "En Cambridge, Inglaterra, Clinton y el Premier británico, John Mayor, rindieron homenaje a los estadounidenses muertos en la guerra y recordaron los acontecimientos decisivos de hace 50 años que marcaron el final del nazismo" (El Mercurio, 5-VI-94, p. A 12, c. 4).

aspirina (analgésico basado en el ácido acetilsalicílico, de propiedades antipiréticas y antiinflamatorias) < al. Aspirin. Este término fue acuñado en 1899 en Alemania como marca comercial.

autismo < al. Autismus, término usado por primera vez en 1911 por el famoso psiquiatra suizo Eugen Bleuler (1857-1940) que contribuyó notablemente al estudio y entendimiento de las enfermedades mentales. "El autismo o los trastornos del espectro autista afectan cómo una persona se comunica, relaciona e interactúa con otros." (A este mecanismo de adaptación para la vida y la supervivencia en los https://www.clinicalascondes.cl), etc.

Conviene observar que en cuanto a estos dos términos la etimología que propone la RAE es diferente; de esta manera, la etimología de aspirina sería "aspirina $\mathbb{}{ }^{\circledR}$ marca registrada" y el término del latín científico AUTISMUS, respectivamente, y

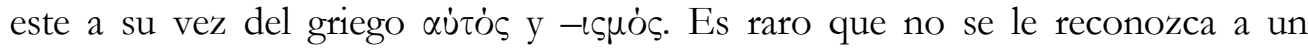
concepto usado por primera vez en alemán, con el significado presentado en el DRAE la primacía y se considere que la etimología correcta sean los términos latinos y griegos, lenguas en las cuales no existía este concepto. Lo mismo vale para aspirina, que, desde luego, es una marca registrada por la compañía alemana Bayer, y el nombre que se inventó Bayer es Aspirin. Pero antes de que lo fuese, fue inventada por los alemanes que la nombraron como tal.

Otros términos constituyen el grupo de los préstamos no adaptados ${ }^{3}$ ni consignados en el DRAE (con una frecuencia de uso variable) y están relacionados a:

\footnotetext{
${ }^{3}$ Estos términos están marcados con asterisco *.
} 
-la gastronomía

*apfelwein (sidra de manzanas) < al. Apfelwein, "Y, por cierto, la Apfelwein, sidra de manzanas" (El Mercurio, 12-1-92, Revista del Domingo, p. 16, c. 1),

*apfelstrudel (tarta de manzana) < al. Apfelstrudel "Al momento de la degustación, había [...] para todos los paladares. Se hizo notar [...] la colonia alemana con sus guisos nórdicos (repollo morado) y su repostería típica (apfelstrudel, kuchen)" (El Mercurio, 17-VII-94, Revista del Domingo, p. 9, c. 2), etc.

*knodel < al. Knödel,

$*$ Riesling $<$ variedad de vino de uva blanca originaria de la región alemana del Rin.

* Gewürtztraminer, vino de uva muy aromática, propia de los climas fríos.

*Delikatessen

* bratwurst $<$ al. Bratwurst, salchicha alemana, que se puede freír o asar.

$*_{\text {weisswurst }}<$ al. Weisswurst'salchicha blanca' propia de Baviera.

*Wiener schnitzel < al. Wiener Schnitzel 'escalope a la vienesa'

* Tarta Sacher Sachertorte

* Schwarzbrot < al. Schwarzbrot 'pan negro, pan de centeno, pan moreno'

* Selva negra < al. Schwarzwaldtorte, tarta típica de la Selva Negra, elaborada con crema, chocolate y frutas del bosque.

-la medicina / biología:

*enfermedad de Alzheimer < al. Alzheimer-Krankheit) ingl. Alzheimer's desease, fr. maladie d'Alzheimer (semi)calco semántico

* síndrome de Asperger < al. Asperger-Syndrom.

*Hombre de Neanderthal término usado para referir a los fósiles humanos descubiertos en el valle de Neander (Neanderthal), cerca de Dusseldorf.

*edelweiss $<$ al. Edelweiss 'flor de las nieves' Leontopodium alpinum

-las artes:

* Sezession / Jugendstil < al. Sezession, Jugenstil 'El movimiento artístico renovador de finales del s. XIX, principios del s. XX con características particulares en los diferentes países europeos que adoptó diversas denominaciones Art Nouveau en Francia y Bélgica, Modern Style en Inglaterra, Jugendstil en Alemania, Sezession en Austria y Liberty o Floreale en Italia, Modernismo en España.

* Biedermeier < Biedermeier, denominación de un estilo artístico desarrollado en la Europa Central a principios del s. XIX.

* Bildungsroman < al. Bildungsroman 'novela de formación o aprendizaje.

* bauhaus escuela de artesanía, diseño, arte y arquitectura fundada en 1919 por Walter Gropius quien sentó las bases del siseno industrial y gráfico. 
-política, historia, sociedad:

*Áfrika Korps < al. Afrkakorps. Se trata del nombre de las tropas alemanas capitaneadas por el general Rommel, que entre 1941-1943 lucharon contra los británicos en el norte de África apoyando al ejército italiano de allí. "Como comandante del Áfnca Korps, Rommel había resucitado el estilo caballeresco de combatir olvidado hacía mucho." (El Mercurio, 16-1-94, p. D26, c. 6).

*Anschluss < al. Anscbluss (término usado para referir a la anexión de Austria por Hitler el 12 de marzo 1938. "La imagen de Kurt Waldheim estará bajo la lupa en marzo cuando los austríacos recuerden el 'Anschluss, la anexión de Austria por el Tercer Reich de Adolfo Hitler en 1938" (Las Últimas Noticias, 22-1-88, p. 9, c. 1).

*Bundesliga $<$ al. Bundesliga 'Liga Federal de Fútbol'

*Bundesrat < al. Bundesrat 'Consejo Federal', el órgano de representación de los dieciséis estados federales (Länder) de Alemania.

*Bundestag $<$ al. Bundestag 'El Parlamento Federal'

* Bundeswehr $<$ al. Bundeswehr 'Defensa Federal', las fuerzas armadas unificadas de la Alemania de hoy.

*Blitzkrieg < al. Blitzkerieg táctica militar que consta de un bombardeo inicial, seguido de un ataque veloz y sorprendente de las fuerzas móviles a fin de que el enemigo no pueda llevar a cabo una defensa coherente. "La jerarquía militar soviética está procediendo a una reactualización de su doctrina militar, con el propósito de elaborar una moderna versión de la guerra relámpago (blitzkrieg) alemana de los años 40 que permita ganar un conflicto en Europa empleando sólo armas convencionales, según un trabajo de un analista británico." (El Mercurio, 13-XII-83, p. A9, c.1).

* Diktat < al. Diktat refiere a los Arbitrajes de Viena (de 1938 y 1940) cuando la Alemania nazi e Italia fascista -para satisfacer las reivindicaciones territoriales de Hungría- le restituyen parte de los territorios que había perdido en 1920 tras el Tratado de Trianon.

*Führer < al. Führer, palabra que significa 'jefe, líder, guía o conductor' usado comúnmente en Alemania para referirse a lideres de cualquier campo de actividad. Usado fuera de Alemania, se refiere a Adolf Hitler.

* gastarbeiter < al. Gastarbeiter, 'trabajador 'invitado', término concerniente a los trabajadores de diversas nacionalidades que fueron contratados durante la década de los ' 60 por las autoridades de la RFA.

*Gestapo < al. Gestapo, contracción de Geheime Staatspolizei 'Policía Secreta del Estado', la policía secreta oficial de la Alemania nazi. 
* Lebenstaum < al. Lebensraum 'espacio vital', expresión acuñada por el geógrafo Friedrich Ratzel (1844-1904) utilizada por Hitler para justificar su política exterior.

*Luftwaffe $<$ al. Luftwaffe 'fuerza aérea de Alemania'.

* Ostpolitik < al. Ostpolitile 'Política del este'. El término refiere a la política de acercamiento al bloque soviético durante la Guerra Fría, proceso político iniciado por Willy Brandt (socialdemócrata que fue alcalde del Berlín occidental, ministro de asuntos exteriores y canciller de la RF de Alemania) con vistas a normalizar las relaciones con la Europa del Este y, especialmente, con la URSS.

*Putsch $<$ al. Putsch 'acción armada de un grupo político-militar a fin de derrocar el poder del estado a través de un ataque inesperado'. "El Presidente soviético, Mijail Gorvachov, reveló hoy que desoyó una advertencia directa del Presidente George Bush acerca de una intentona golpista antes del putsch de agosto." (La Tercera de la Hora, 13-XI-91, p. 20, c. 3).

* Rathaus $<$ al. Rathaus 'ayuntamiento'.

* Reich < al. Reich el nombre oficial del Estado alemán entre 1871-1949. "Un grupo de diputados pidió acceder a los informes secretos del Departamento 50, la mítica unidad de la PDI que desbarató células del Tercer Reich en Chile." http://www.latercera.com/noticia/tras-los-archivos-los-cazanazis-chilenos

* Reichsbank < al. Reichsbank, Banco Central de Alemania entre 1876-1945.

* Reichstag < al. Reichstag 'el Parlamento de Alemania' desde 1849 hasta finales de la $2^{a}$ guerra mundial.

* Tercer Reich período de la historia de Alemania entre 1933-1945 cuando gobernó el país el Partido Nacionalsocialista Obrero Alemán.

*Wehrmacht $<$ al. Wehrmacht 'Fuerza de Defensa', el nombre de las fuerzas armadas de la Alemania nazi.

Una veintena de términos de origen neerlandés entrados directamente o por conducto del francés a lo largo de los años, a partir, generalmente, del período de la dominación española en Los Países Bajos hasta nuestros días.

Préstamos directos:

dique $1515<$ nl. dijk

duna $1592<\mathrm{nl}$. duin

escaparate $1616<$ nl. schaprade

flamenco $<$ nl. Vlaming 'habitante de Flandes'

pólder $<$ nl. polder 'terreno pantanoso ganado al mar y que una vez desecado se dedica al cultivo' 
Préstamos indirectos:

babor $1526<\mathrm{nl}$. backboord por conducto del fr. babord.

bauprés $1412<\mathrm{nl}$. boegspriet por conducto del fr. beauprés 'palo grueso, horizontal o algo inclinado en la proa de los barcos.

brandy < nl. brandewijn y este de gebrande wijn 'vino quemado' por conducto del ingl. brandy. Para aumentar la cantidad de vino y facilitar su transporte a Escandinavia, en Los Países Bajos empezaron a destilarlo para que una vez en Escandinavia echarle de nuevo agua. El resultado fue que a los escandinavos les gustó más el 'vino quemado'.

corbeta $1765<$ nl. korver 'buque de caza' por conducto del fr. corvette.

demarrar $<$ nl. marren 'atar' por conducto del fr. demarrer.

escorbuto $1765<\mathrm{nl}$. med. schorbut por conducto del fr. scorbut.

estribor $1526<$ nl. stierboord por conducto del fr. (es)tribord

filibustero $1836<\mathrm{nl}$. vrijbuiter 'corsario' por conducto del fr. flibustier (ant. fribustier).

Flandes / Flandres < nl. Vlaanderen por conducto del fr. Flandres.

flete $1478<\mathrm{nl}$. med. vraecht por conducto del fr. fret.

macarra 'persona agresiva, achulada; vulgar, de mal gusto; rufián' < nl. makreel por conducto del fr. maquereau y el cat. macarró.

maniquí $1708<$ nl. mannekijn dim. de man 'hombre' por conducto del fr. mannequin.

placaje 'en rugby, acción y efecto de placar' $2001<$ nl. plakken por conducto del fr. placage y este derivado de plaquer.

rebenque 1587 'látigo de cuero o cáñamo embreado, con el cual se castigaba a

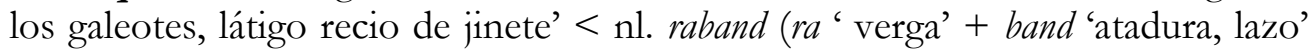
por conducto del fr. raban.

tinglado 1800, derivado del verbo tinglar (conservado en Chile) 'cobertizo ligero, artificio, enredo, maquinación, barrullo de gentes o cosas' < nl. tengel 'tabla' por conducto del fr. tingler, hoy caído en desuso.

Con el descubrimiento y colonización de América, cruzaron el Océano también grupos de gitanos. En su mayoría los grupos gitanos que viven actualmente en Hispanoamérica llegaron en los siglos XIX y XX y declaran ser oriundos de la Europa oriental (Serbia, Rusia, Yugoslavia y Rumania). No obstante, parece que en el tercer viaje de Colón había también dos parejas de gitanos (Salamanca, 2008:211). Pese a su escasa y marginada presencia en la sociedad chilena, unos cuantos términos de origen gitano se usan en el argot. Entre estos figuran los siguientes ejemplos que pertenecen al registro coloquial vulgar: 
gachó 'hombre, proxeneta, amante de una mujer' < caló gachó y este del gitano găgo. El mismo lexema existe también en rumano, gagíu s. m. 'amo, señor, amante', término argótico, como, por lo demás, todos los préstamos del idioma de los gitanos.

pureta 'viejo, anciano' < caló puré, término coloquial despectivo y su cognado rumano puriu $<$ romaní puro 'viejo'.

En el DRAE aparece el verbo jalar con los siguientes significados: 1. halar 'tirar de un cabo' 2. 'tirar de algo o de alguien' 3. 'comer con mucho apetito' 4. 'aspirar con fuerza el humo del cigarro' 5. 'emborrachar' 6. 'esnifar'. Sin embargo, teniendo en cuenta que el $3^{\text {er }}$ significado no está de ninguna manera relacionado con los dos primeros y que se trata de un término coloquial, su 'étimo podría ser otra. En el rumano coloquial y argótico hay un verbo a hali que tiene el mismo significado ‘comer rápidamente y con mucho apetito' y cuyo 'étimo es el verbo romaní balo 'comer'. Es muy posible que el verbo español jalar / halar tenga el mismo étimo.

A principios del siglo pasado entraron en Chile, especialmente en Santiago, el tango y la milonga, la música tradicional de Buenos Aires y con ella también muchos lunfardismos. Todos los que siguen, a excepción de mina, están consignados en el DRAE.

canchero 'hábil, que tiene cancha'.

gauchada 'servicio o favor ocasional prestado caton buena disposición' < gaucho. gil 'persona simple, incauta, de poco entendimiento < caló gilí.

laburo 'trabajo', inicialmente 'robo' en el argot carcelario < it. lavoro.

¡qué macana! interjección para expresar contrariedad.

macanear 'decir mentiras o desatinos'.

macanudo < macana + -udo ' bueno, magn'ifico, extraordinario' excelente en sentido material y moral'.

mina 'mujer linda y sexualmente interesante'.

mufa 'enfado o mal humor por algo que molesta'.

pibe 'muchacho, adolescente, joven' < esp. pebete y este del cat. pevet. Esta etimología es discutible, puesto que este lunfardismo no existió hasta finales del s. XIX cuando llegaron numerosísimos inmigrantes italianos, entre los cuales también los ligures, en cuyo dialecto pibe significaba 'aprendiz, muchacho de los mandados'

piola 'tranquilo, callado, simpático, de trato agradable' < lat. pediŏla.

En Chile, Argentina y Uruguay existe el lexema punga 'ladrón, carterista' de etimología desconocida. En rumano el sustantivo pungă significa 'saquito con dinero, bolsa' del cual se derivó toda una familia de palabras: el verbo a pungi 
'robar', y el sustantivo pungaş 'ladrón', el verbo a pungăşi 'robar', el sustantivo pungăşie 'robo'. Es muy posible que también en este caso se dé una relación de parentesco entre el término español y el rumano, ya que en romaní existe el sustantivo phungia 'saco'.

quilombo 1890 'prostíbulo' < bantú quilombo 'refugio clandestino a modo de refugio’ al que acudían los esclavos fugitivos.

Desde el punto de vista diacrónico se ha podido ver que el léxico español de Chile se caracteriza por:

- numerosos términos de origen quechua y mapuche;

- términos de origen germánico que entraron en español en tres etapas diferentes: en la alta Edad Media, debido a las invasiones de la Península Ibérica por las tribus germánicas, a finales del Renacimiento, más exactamente durante el siglo XVI, debido a la llegada de los Habsburgo a España y en la época contemporánea, como resultado del desarrollo científico y económico de Alemania, así como también de la triste historia en la primera mitad del siglo pasado;

- términos de origen neerlandés que, generalmente, reflejan una realidad geográfica específica o están relacionados a la marina e ilustran los contactos que España ha tenido a lo largo de los siglos con Los Países Bajos;

- algunos lunfardismos y términos de origen gitano que entraron en el español de Chile en el siglo XX.

\section{Bibliografía}

Branza, Mircea-Doru. 2009. "Un experimento de cambio lingüístico. El leísmo en España e Hispanoamérica: divergencias y convergencias" Analele Universităţii din București, Limbi şi literaturi străine, anul LVIII, partea a II-a. 71-97.

Branza, Mircea-Doru. 2011. "Norma y 'antinorma' en el español estándar de España e Hispanoamérica: el caso del leísmo masculino y femenino de persona" Tkáćiková, Eva (ed.). Philologia XXI. Supplementum II. Autre - autrui - altérité / El otro - lo otro - la otredad / Altro - l'altro - l'alterità. Bratislava: Univerzita Komenského Bratislava. 36-47.

Branza, Mircea-Doru. 2012. "La variación 'circular': la diacronía del voseo chileno y las causas de su actual difusión" Colindancias, Revista de la Red Regional de Hispanistas de Hungría, Rumanía y Serbia, 3, Editura Universității de Vest. 141-153. 
Branza, Mircea-Doru. 2015. "Continuidad y cambio lingüísticos en el mundo hispanohablante" Quaestiones Romanicae III/2. Colocviul internațional Comunicare și cultură in Romania europeană, ediția a III-a, 3-4.10.2014, Timişoara/Szeged: EUV/JATE Press. 608-625.

Branza, Mircea-Doru. 2017. "Lengua e identidad nacional: el caso de Chile" Festschrift for Professor Smaranda Elian. Bucarest: Universidad de Bucarest (en prensa).

Corominas, Joan y Pascual, José. 1983. Diccionario crítico etimológico castellano e bispánico. Madrid: Gredos.

Prieto, Luis. 2002-2003. "Germanismos en el léxico de la prensa de Santiago de Chile" Boletin de Filologia de la Universidad de Chile XXXIX. 141-267.

Prieto, Luis. 2006. "Quechuismos en el léxico de la prensa de Chile" Boletín de Filología de la Universidad de Chile, XLI. 97-196.

Rabanales, Ambrosio. 1995. "El estudio del habla culta de Santiago de Chile" Thesaurus, Revista del Instituto Caro y Cuervo, Bogotá, Tomo L. 51-68.

Rabanales, Ambrosio. 2000. "El español de Chile: presente y futuro" Onomazein, 5, Santiago de Chile. 135-141.

Salamanca, G. F. dr. 2008. "Morfología nominal del rromané, lengua de los gitanos de Chile (I)" Literatura y lingüística 19. 211-233. Fecha de consulta: 10 de octubre de 2017. Asequible en: http://dx.doi.org/10.4067/S0716-58112008000100012.

Salamanca, Gastón. 2010. "Apuntes sociolingüísticos sobre la presencia de argentinismos en el léxico del español de Chile" Atenea (Concepción), 502. 125-149. Fecha de consulta: 10 de octubre de 2017. Asequible en: http://dx.doi.org/ 10.4067/S0718-04622010000200008.

Salamanca, Gastón-Cofré, Katherine-Gutiérrez, Abel. 2011. “Tío, deje una moneíta: consideraciones lingüísticas sobre un uso no literal de los términos de parentesco en el español de Chile" Alpha, 32. 167-180. Fecha de consulta: 14 de octubre de 2017. Asequible en: http://dx.doi.org/10.4067/S0718-22012011000100013.

Salamanca Gutiérrez, Gastón Felipe-Valenzuela Hidalgo, Alejandro Andrés. 2013. "Argentinismos en el léxico del español de Chile: resultados de un trabajo de campo realizado con 23 sujetos de Concepción y 23 sujetos de Buenos Aires" Linguiistica y literatura, 63. 235-253.

Salamanca, Gastón-Ramírez, Ariella. 2014. "Argentinismos en el léxico del español de Chile: nuevas evidencias" Atenea, 509. 97-121. Fecha de consulta: 15 de octubre de 2017. Asequible en: http://dx.doi.org/10.4067/S0718-04622014000100006. 
Sánchez Cabezas, Gilberto. 2010. "Los mapuchismos en el DRAE" Boletin de Filología, tomo XLV(2). 149-256. Fecha de consulta: 16 de octubre de 2017. Asequible en: http://dx.doi.org/10.4067/S0718-93032010000200008.

Ziebur, Ulrike. 2000. "Die soziolinguistische Situation von Chilenen deutscher Abstammung" Weidt, Harald (ed.). Linguistiek online, n. ${ }^{\circ} 3$. Frankfurt an der Oder.

Online Synonym-Wörterbuch | Synonyme, Fremdwörter \& Antonyme http://synonyme.woxikon.de/synonyme/konkurrenz.php 